University of Nebraska - Lincoln

DigitalCommons@University of Nebraska - Lincoln

$11-1-1982$

\title{
Magnetic properties of hydrides of rare earth-transition metal glasses
}

C.G. Robbins

University of Nebraska - Lincoln

Z.D. Chen

University of Nebraska - Lincoln

J.G. Zhao

University of Nebraska - Lincoln

Michael J. O'Shea

University of Nebraska-Lincoln, mjoshea@phys.ksu.edu

David J. Sellmyer

University of Nebraska-Lincoln, dsellmyer@unl.edu

Follow this and additional works at: https://digitalcommons.unl.edu/physicssellmyer

Part of the Physics Commons

Robbins, C.G.; Chen, Z.D.; Zhao, J.G.; O'Shea, Michael J.; and Sellmyer, David J., "Magnetic properties of hydrides of rare earth-transition metal glasses" (1982). David Sellmyer Publications. 158.

https://digitalcommons.unl.edu/physicssellmyer/158

This Article is brought to you for free and open access by the Research Papers in Physics and Astronomy at DigitalCommons@University of Nebraska - Lincoln. It has been accepted for inclusion in David Sellmyer Publications by an authorized administrator of DigitalCommons@University of Nebraska - Lincoln. 


\title{
Magnetic properties of hydrides of rare earth-transition metal glasses
}

\author{
C. G. Robbins, Z. D. Chen, ${ }^{*}$ J. G. Zhao, ${ }^{*}$ M. J. O'Shea, and D. J. Sellmyer \\ Behlen Laboratory of Physics, University of Nebraska, Lincoln, Nebraska 68588
}

\begin{abstract}
The effect of hydrogen on magnetic properties of metallic glasses of the form $\left(\mathrm{R}_{80} \mathrm{Ga}_{20}\right)_{1-} \mathrm{T}_{\mathrm{x}} \mathrm{H}_{\mathrm{y}}$ where $\mathrm{R}=\mathrm{Pr}$, $\mathrm{Nd}, \mathrm{Gd}, \mathrm{Tb}, \mathrm{Er} ; \mathrm{T}=\mathrm{Cr}, \mathrm{Fe}, \mathrm{Co}, \mathrm{B} ; 0 \leq \mathrm{x} \leq 0.3$ and $0 \leq \mathrm{y} \leq 1.7$ is reported. The anisotropic rare earth glasses without $\mathrm{H}$ all exhibit speromagnetic (spin-glass-like) transitions and the effect of hydrogen, in most cases, is to lower the peak in $\chi_{\text {ac }}$ significantly but leave $T_{C}$ relatively unchanged. For the Gd glass with $T=F e$ and $x=0.1$ the introduction of $H$ at the level $y=0.55$ causes a large decrease in $T_{C}$ and a significant increase in local random anisotropy. Models for these phenomena are discussed.
\end{abstract}

PACS numbers: $75.50 . \mathrm{Kj}, 81.40 . \mathrm{Rs}, 75.30 . \mathrm{Kz}$

INTRODUCTION

The experimental study of the magnetic properties of crystalline rare earth-transition metal alloy hydrides has seen much activity in the last decade $[1,2]$. There are several reasons for this. Almost all of the elemental rare earths (hereafter denoted collectively by $R$ ) absorb hydrogen to H/R ratios of 3 , a relatively high value, and those which do not (Eu and $Y b$ ) easily achieve 22 as a maximum [3]. In addition, there exist many crystalline rare earth transition metal intermetallic compounds which are excellent hydrogen absorbers even if the transition metal is not $[4,5]$. According to the simplest anionic model, electrons are removed from the conduction bands of the alloy to fill the hydrogen is shell (and form $\mathrm{H}^{-}$) and thus deplete the electrons available to mediate the indirect (RKKY) R-R and R-T exchange interactions [4].

During the last several years, interest in the magnetic properties of unhydrogenated rare-earthrich metallic glasses has been developing in this and other laboratories $[6,7]$. This is in part due to the discovery of very large coercive forces in some of these materials, e.g., amorphous $\left(\mathrm{Pr}_{80} \mathrm{Ga}_{20}\right)_{1-x} \mathrm{Fe}_{x}$ and $\left(\mathrm{Tb}_{80} \mathrm{Ga}_{20}\right)_{1-x} \mathrm{Fe}_{x}[7]$. The results obtained from these studies, coupled with what was known about both unhydrogenated and hydrogenated crystalline R-T alloys strongly suggested that an investigation into the effect of hydrogen on some of the magnetic properties of amorphous $\left(R_{80} G_{20}\right)_{1-x^{\top} x}$ alloys would be of interest. This report presents the initial results obtained from such a study. All amorphous specimens were fabricated by splatcooling arc melted droplets of appropriate compositions. Each splat was then cut into two approximately equal pieces, one of which was hydrogenated by electrolysis in very dilute $\mathrm{H}_{2} \mathrm{SO}_{4}$. The hydrogen uptake was measured, where possible, by weighing the specimen before and after charging. A few samples were subjected to MoK $\alpha x$-ray analysis which invariably showed the pattern of the amorphous state with no sign of the sharp lines associated with crystallinity. Both the hydrogenated and unhydrogenated splats were then rolled into nonmagnetic tape to make two $20 \mathrm{mg}$ cylindrical specimens for placement with in the coils of an a.c. susceptibility apparatus operating at 280 $\mathrm{Hz}$. Each sample was then immersed in liquid helium and its a.c. response measured as a function of the temperature $(4.2 \leqslant T \leqslant 290 \mathrm{~K})$ as the specimen was slowly withdrawn from the cryogenic liquid. Thermal contact between the specimen and the Si diode thermometer was insured by keeping both in mechanical contact
Table 1

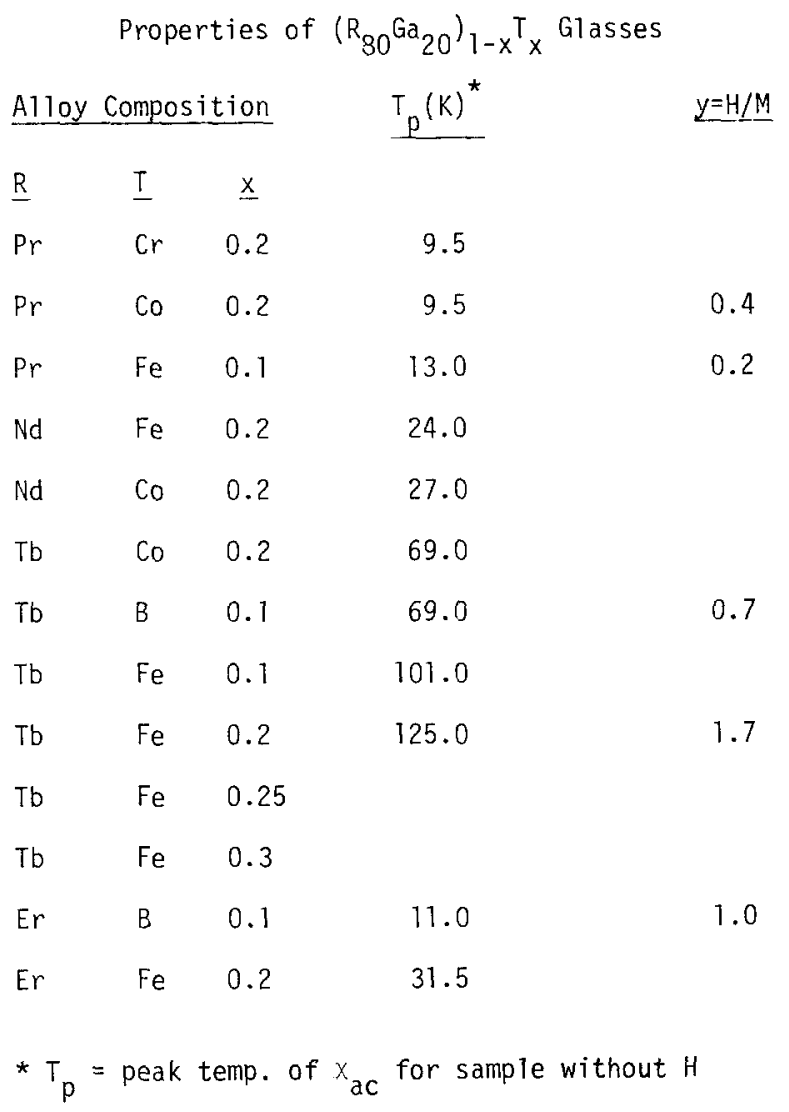

with a sapphire crystal. The d.c. magnetization of one specimen was also measured as a function of applied field (up to $80 \mathrm{kOe}$ ) and temperature $(4.2 \leqslant T \leqslant 170 \mathrm{~K})$ in a vibrating sample magnetometer which has been described in detail elsewhere [8]. A11 hydrogenated splats were stored in liquid nitrogen when not in use unless they were purposely undergoing a room temperature anneal.

\section{EXPERIMENTAL RESULTS AND DISCUSSION}

A list of most of the anisotropic amorphous alloys (all except those containing $G d$ ) is given in Table 1. In most cases, the temperature dependence of the a.c. susceptibility exhibited only a single peak between 4.2 and $290 \mathrm{~K}$, irrespective of the hydrogen content of the specimen. Figure 1 shows a 


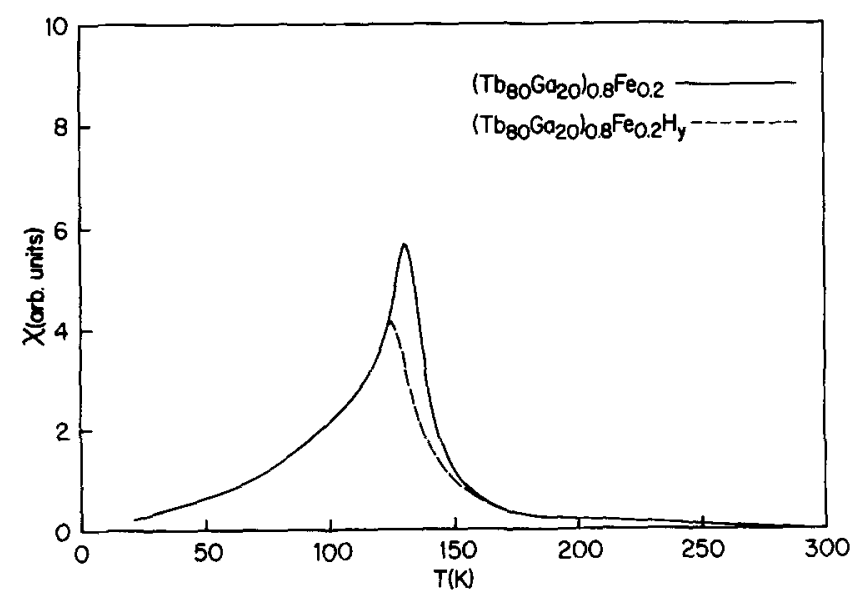

Figure 1: a.c. susceptibility of unhydrogenated and hydrogenated $\left(\mathrm{Tb}_{80} \mathrm{Ga}_{20}\right)_{0.8} \mathrm{Fe}_{0.2}$ as a function of temperature.

typical example of this behavior which is often associated with speromagnetism in these alloys [9]. The temperature of this peak is also given for all alloys of this type in column 2 of Table 1 . The introduction of hydrogen into any given specimen always lowers the amplitude and does not greatly affect the peak temperature. This suggests the existence of a two-phase glass, with the phase high in $H$ concentration having a magnetic transition temperature less than $4.2 \mathrm{~K}$, a fact which would require a miscibility gap in the phase diagrams of these alloys with hydrogen (and an attractive $\mathrm{H}-\mathrm{H}$ interaction within the alloys) similar to that found in $\mathrm{PdH}_{x}[10]$. Compositions showing a more complex temperature dependence of the susceptibility have no entry in column 2 of Table 1; their a.c. response will be described below. Column 3 of Table 1 gives approximate atomic hydrogen-to-metal (H/M) ratios for all the hydrogenated alloys which did not break up and did not suffer acid attack during the hydrogenation process.

The temperature dependence of $x_{a c}$ for

$\left(\mathrm{Tb}_{80} \mathrm{Ga}_{20}\right)_{0.7} \mathrm{Fe}_{0.3}$ is shown in Figure 2. For the sample without $H$, two magnetic transitions are evident. The origin of these two peaks is likely to be a phase separation into Fe-rich and Fe-deficient amorphous regions with in the specimen. This phenomenon has been found in the $\left(\mathrm{Pr}_{80} \mathrm{Ga}_{20}\right){ }_{1-x} \mathrm{Fe}$ system for $x \geqslant 0.2[7]$. The effect of hydrogen on the a.c. susceptibility of this sample was to annihilate the narrower high temperature peak associated with the Fe-rich amorphous phase while reducing the amplitude of the broader peak situated at lower temperatures. Afterward, a two week anneal at room temperature led to a partial restoration of the high temperature peak at $200 \mathrm{~K}$ (see curve 3 of Fig. 2), a fact which

\section{Table 2}

Ordering Temperatures $T_{C}$ for $\left(G_{80} G_{20}\right)_{1-x}{ }^{\top} x$ Glasses

\section{Alloy Composition}

$\begin{array}{ccc}I & \underline{x} & \underline{T_{c}(K)} \\ B & 0.1 & 125 \\ B & 0.2 & 149 \\ \mathrm{Fe} & 0.05 & 151 \\ \mathrm{Fe} & 0.1 & 174 \\ \mathrm{Fe} & 0.2 & 220\end{array}$

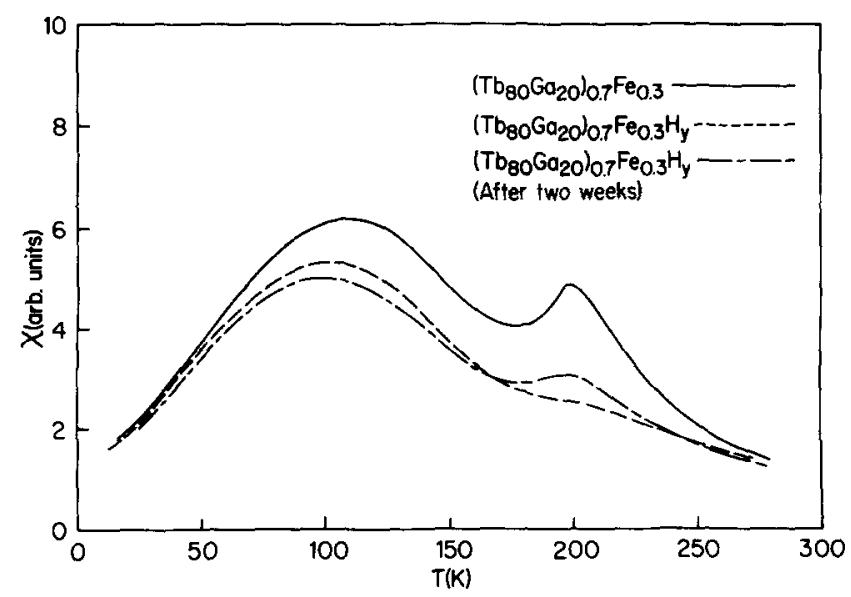

Figure 2: a.c. susceptibility of unhydrogenated, hydrogenated and hydrogenated but after a 2-week anneal at room temperature $\left(\mathrm{Tb}_{80} \mathrm{Ga}_{20}\right)_{0.70} \mathrm{Fe}_{0.3}$ as a function of temperature.

suggests the presence of a miscibility gap in the phase diagram spanning the "high-Fe" amorphous phase in this alloy with hydrogen.

All of the unhydrogenated alloys containing Gd exhibit a temperature dependence of the a.c. susceptibility which is usually associated with ferromagnetism, i.e., a relatively high plateau where the susceptibility is infinite. This is seen in Fig. 3 which also shows a low-temperature falloff of $x_{a c}$ which signals the presence of an hysteretic phase. Table 2 gives the value of $T_{C}$ for each urhydrogenated alloy tested. The introduction of hydrogen into $\left(\mathrm{Gd}_{80} \mathrm{Ga}_{20}\right)_{0.9^{\mathrm{B}} 0.1},\left(\mathrm{Gd}_{80} \mathrm{Ga}_{20}\right)_{0.8^{\mathrm{B}}} 0.2$ and $\left(\mathrm{Gd}_{80} \mathrm{Ga}_{20}\right)_{0.95} \mathrm{Fe}_{0.05}$ had the effect of washing out the sharpness of the ferromagnetic transition (a fact which can be attributed to inhomogeneities in the hydrogen concentration with in the specimen) and lowering the value of $T_{c}$, as illustrated by curve 2 in Fig. 3. Small amounts of hydrogen $(y=0.3)$ placed into $\left(\mathrm{Gd}_{80} \mathrm{Ga}_{20}\right)_{0.8} \mathrm{Fe}_{0.2}$ also lowered the value of $\mathrm{T}_{\mathrm{C}}$ (from 220 to $197 \mathrm{~K}$ ) but left the transition fairly sharp. However, the introduction of 255 at. $\%$ hydrogen $(H / M=1.3)$ into a specimen of amorphous $\left.{ }^{(G d} 0^{G a_{20}}\right)_{0.9} \mathrm{Fe}_{0.1}$ altered the temperature dependence of its a.c. susceptibility from a "ferromagnetic" curve of the type described just above $\left(T_{c}=174 \mathrm{~K}\right)$

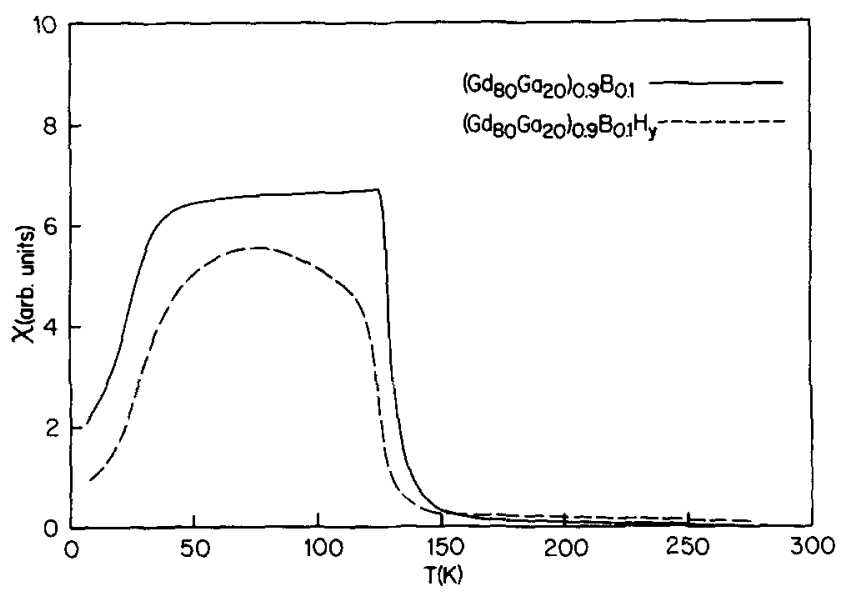

Figure 3: a.c. susceptibitity of unhydrogenated and hydrogenated $\left(\mathrm{Gd}_{80} \mathrm{Ga}_{20}\right)_{0.9} \mathrm{~B}_{0.1}$ as a function of temperature. 


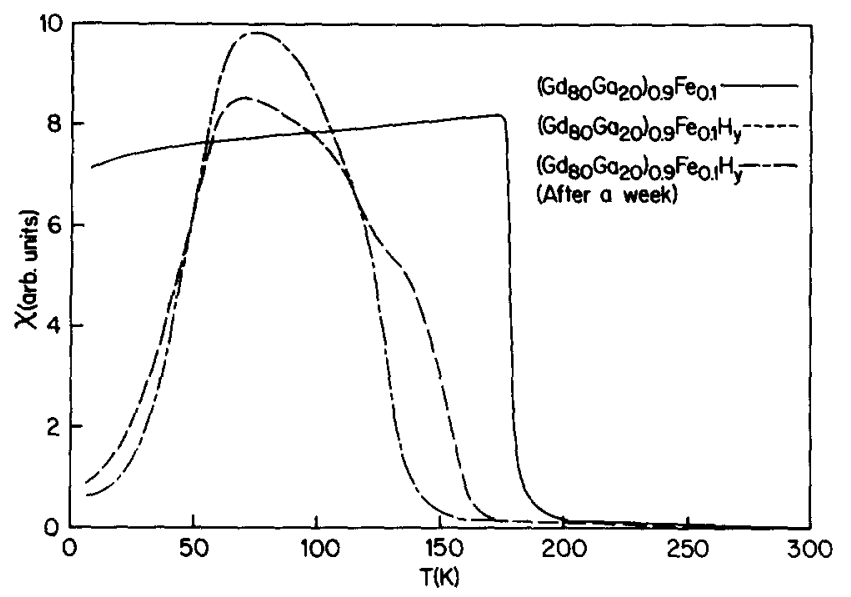

Figure 4: a.c. susceptibility of unhydrogenated, hydrogenated and hydrogenated but after a 1-week anneal at room temperature $\left(\mathrm{Gd}_{80} \mathrm{Ga}_{20}\right)_{0.9} \mathrm{Fe}_{0.1}$ as a function of temperature.

to a curve which exhibits a single peak at $\approx 67 \mathrm{~K}$ (see Fig. 4). A room temperature anneal of 1 week raised the amplitude of this peak and the temperature of its maximum from $\sim 67 \mathrm{~K}$ to $277 \mathrm{~K}$ (curve 2 to curve 3 in Fig. 4). Since this sort of peak in the a.c. susceptibility is of a type often associated with speromagnetism, it was decided to measure the d.c. magnetization of these two specimens (hydrogenated and unhydrogenated) for applied fields up to $80 \mathrm{kOe}$ in a vibrating sample magnetometer.

One result of these measurements can be seen in the two hysteresis loops - one each for unhydrogenated and hydrogenated amorphous $\left(\mathrm{Gd}_{80} \mathrm{Ga}_{20}\right)_{0.9} \mathrm{Fe}_{0.1}$ taken at $4.2 \mathrm{~K}$ and exhibited in Fig. 5. The introduction of hydrogen into this specimen markedly increased the slope of the sample magnetization (M) versus applied field $(H)$ curve - obtained for decreasing $\mathrm{H}$ - at all values of $\mathrm{H}$ except possibly the very lowest. Since it has been previously shown [6] that the magnetic anisotropy energy of an amorphous specimen (D) is proportional to the area between the $M(H)$ curve for descending $H$ and the $M$ axis, it is clear from Fig. 5 that one effect of $\sim 55$ at. \% $\mathrm{H}$ on this amorphous material is to increase the value of $D$ by a very large factor. In addition, the contemporaneous decline in the magnetic ordering temperature from $175 \mathrm{~K}$ to $\sim 67 \mathrm{~K}$ (or $\approx 77 \mathrm{~K}$ after room temperature anneal) indicates that the hydrogen also causes a sharp lowering of the specimen exchange energy ( $J$ ). Thus, it seems clear that the value of $D / J$ has been significantly increased by the introduction of 55 at. $\% \mathrm{H}$ into amorphous $\left(\mathrm{Gd}_{80} \mathrm{Ga}_{20}\right)_{0.9} \mathrm{Fe}_{0.1}$. The concomitant change in magnetic properties from the infinite susceptibility phase towards speromagnetism as $\mathrm{D} / \mathrm{J}$ is increased is consistent with other research on rareearth glasses where the same phenomenon was observed [11].

In summary, our initial results on $H$ absorption in the anisotropic rare-earth glasses suggest a phase separation into $\mathrm{H}-\mathrm{rich}$ and $\mathrm{H}$-deficient regions, with the magnetic transition of the H-rich region being below $4.2 \mathrm{~K}$. For the Gd glasses the evidence favors a homogeneous glass in which $\mathrm{H}$ significantly increases the anisotropy, decreases the average exchange energy, and changes the magnetic structure to speromagnetic. The ability of these rare-earth glasses to absorb relatively large amounts of hydrogen indicates that they are worthy of further study, which we are actively pursuing in our laboratory.

We are grateful to $\mathrm{Mr}$. J. Nabity for fabrication of the glasses and to the National Science Foundation (DMR-8110520) for their support of this research.

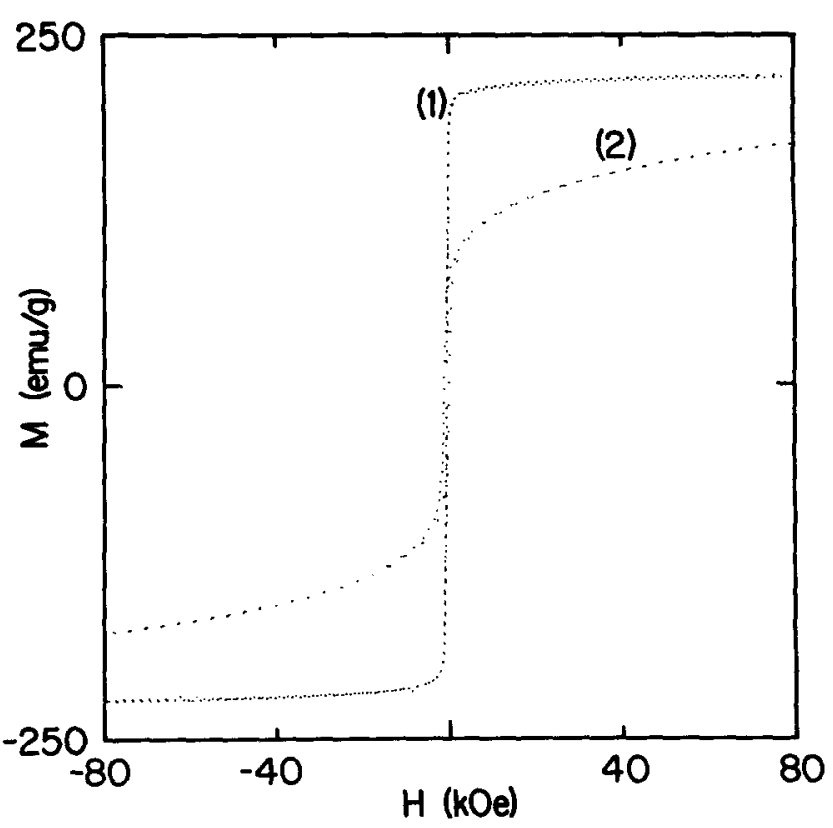

Figure 5: Hysteresis loops at $4.2 \mathrm{~K}$ for unhydrogenated (curve 1) and hydrogenated (curve 2) $\left(\mathrm{Gd}_{80} \mathrm{Ga}_{20}\right)_{0.9} \mathrm{Fe}_{0.1}$.

\section{REFERENCES}

* On leave from Institute of Physics, Academia Sinica, Beijing.

1. H. Zijlstra and F.F. Westendorp, Sol. St. Comm. 7, 857 (1969).

2. J.H.N. van Vucht, F.A. Kuijpers and H.C.A.M. Bruning, Phil. Res. Rep. 25, 133 (1970).

3. W.E. Wallace, in Hydrogen in Metals I, Edited by G. Alefeld and J. Volk1, Springer-Verlag, Berlin, Heidelberg, New York (1978) p. 169.

4. W.E. Wallace, in Metallic Hydrides, Edited by G. Bambakides, Plenum Press, New York and London (1981) p. 21.

5. R. Wiswal, in Hydrogen in Metals II, Edited by E. Alefeld and J. Volk1, Springer-Verlag, Berlin, Heidelberg, New York (1978) p. 201.

6. G. Hadjipanayis, $0 . J$. Sellmyer, and B. Brandt, Phys. Rev. B 23, 3349 (1981), and refs. therein.

7. See: S.G. Cornelison, D.J. Sellmyer, J.G. Zhao and Z.D. Chen, J. Appl. Phys. 53(3), 2330 (1982) and references therein.

8. J.A. Gerber, W.L. Burmester and D.J. Sellmyer, Rev. Sci. Instrum. 53, 691 (1982).

9. S.G. Cornelison, Ph.D. Thesis, University of Nebraska, 1982 (unpublished).

10. H. Frieshe and E. Wicke, Ber. Bunserges Physik Chem. 77, 50 (1973).

11. M.J. O'Shea, S.G. Cornelison, and D.J. Sellmyer, Buti. Am. Phys. Soc. 27, 412 (1982), and to be published. 